\title{
Byzantinische Ziegelstempel.
}

Die Stempel und Fabriksmarken der byzantinischen Flachziegel bilden bekanntlich mit ihrem Text, der Indiktionenzahl und den Monogrammen des öftern nicht uninteressante Datumsbelege und verdienen daher eine gewisse Beachtung. Leider sind die meisten, von alten Bauten herrührenden Ziegel - in Konstantinopel wenigstens - dem Untergange geweiht, da ihr gutes Material bei Neubauten zur Herstellung des Mörtels, des „Khorassan“, verwendet wird.

Eingedenk des Diktums "Colligite fragmenta, ne pereant" habe ich seit einiger Zeit solche mit Stempeln versehene Ziegel, wo immer erhältlich, gesammelt und teile nachstehend deren Text mit, in der Annahme, daB auch der geringste Beitrag für unsere byzantinischen Studien von Interesse sein dürfte:

Nr. 1 stammt von der Stadtmauer des Theodosios und wurde beim Adrianopeler Tor gefunden:

\section{+ AANO(EMIOY)}

wohl der Stempel des ersten Erbauers der Stadtmauern, des praefectus praetorio Anthemius, aus dem Jahre 413.

Nr. 2

$+\Theta € O \Phi I$

ヘOY +

Ziegelstempel des Kaisers Theophilos.

Nr. 3 und 4 Fragmente:

$$
\begin{aligned}
& \text { MAPTY(POE?) } \\
& +\mathrm{I}(\mathrm{N}) \Delta S B \Pi \text {... }
\end{aligned}
$$

alle drei ebenfalls aus der Stadtmauer des Theodosios.

Aus dem Demolitionsmaterial eines byzantinischen Stadtmauerturmes, der bis vor wenigen Jahren am heutigen Platze Emin-Onu dicht beim Aufgang zur Yeni-Dschami ragte und in seinem untern Teil eine Marmorplatte mit dem Inschriftfragment $\mathrm{O} \Delta \mathrm{H} \Gamma$ trug, stammt

Nr. 5:

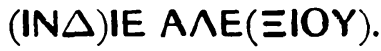

Nr. ỏ ein kieiner Ziegel, in Fener-Bagtsché (Hieria) gefunden: $\mathrm{BACI}(\wedge \mathrm{EIOY})$. 


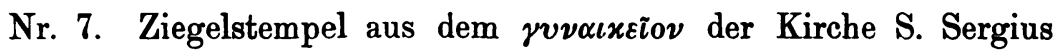
und Bacchus (jetzt Kütschük Agia Sofia) zu Konstantinopel. Dasselbe

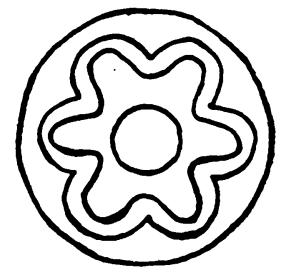

ist in seiner ganzen Ausdehnung mit wohlerhaltenen, achteckigen Flachziegeln gepflastert, von denen einige die hier abgebildete Marke tragen.

Nr. 8 stellt den Bruchteil einer byzantinischen Sonnenuhr dar, gefunden in Haidar-Pascha bei der ehemaligen Eisenbahnstation, wo nach J. Miliopoulos die chalkedonische Kirche der h. Euphemia gestanden haben soll. Das Fragment ist aus Marmor und trägt die Inschrift:

\section{(KYPIE BOHOEI TON(!) $\triangle O Y \wedge O) N C O Y \Theta O \triangle O P(O N)$.}

Die Strahlen entsprechen den Stundenbezeichnungen IB und IA, welche fehlen, der dritte Strahl zeigt noch deutlich die Bezeichnung I (10), die vorhergehende Zahl $\Theta(9)$ erscheint auch noch, allerdings nur zum Teil.

Konstantinopel, 26. Nov. 1907.

J. Gottwald. 